Journal of

Psychopharmacology

\title{
Episodic foresight deficits in regular, but not recreational, cannabis users
}

\begin{tabular}{|c|c|}
\hline Journal: & Journal of Psychopharmacology \\
\hline Manuscript ID & JOP-2017-3272 \\
\hline Manuscript Type: & Original Paper \\
\hline Date Submitted by the Author: & 15-Sep-2017 \\
\hline Complete List of Authors: & $\begin{array}{l}\text { Mercuri, Kimberly; Australian Catholic University, School of Psychology } \\
\text { Terrett, Gill; Australian Catholic University, School of Psychology } \\
\text { Henry, Julie; University of Queensland, Brisbane, Australia, School of } \\
\text { Psychology } \\
\text { Curran, H V; University College London, Sub-department of Clinical Health } \\
\text { Psychology } \\
\text { Elliott, Morgan; Australian Catholic University, School of Psychology } \\
\text { Rendell, Peter G; Australian Catholic University, School of Psychology }\end{array}$ \\
\hline \multirow[t]{2}{*}{$\begin{array}{r}\text { Please list at least } 3 \text { keywords } \\
\text { which relate to your } \\
\text { manuscript:: }\end{array}$} & Episodic foresight, Cannabis, Autobiographical interview \\
\hline & $\begin{array}{l}\text { Cannabis use is associated with a range of neurocognitive deficits, } \\
\text { including impaired episodic memory. However, no study to date has } \\
\text { assessed whether these difficulties extend to episodic foresight, a core } \\
\text { component of which is the ability to mentally travel into one's personal } \\
\text { future. This is a particularly surprising omission given that episodic } \\
\text { memory is considered to be critical to engage episodic foresight. In the } \\
\text { present study, we provide the first test of how episodic foresight is affected } \\
\text { in the context of differing levels of cannabis use, and the degree to which } \\
\text { performance on a measure of this construct is related to episodic memory. } \\
\text { Sixty-one regular cannabis users ( } 23 \text { recreational, } 33 \text { regular) and } 57 \\
\text { controls were assessed using an adapted version of the Autobiographical } \\
\text { Interview. The results provide evidence of a dose response relationship } \\
\text { between cannabis-related impairment and both episodic foresight and } \\
\text { episodic memory, with regular-users exhibiting greater impairment than } \\
\text { both the recreational user and control groups. These data therefore show } \\
\text { for the first time that cannabis related disruption of cognitive functioning } \\
\text { extends to the capacity for episodic foresight, and are discussed in relation } \\
\text { to their potential implications for functional outcomes in this group. }\end{array}$ \\
\hline
\end{tabular}


2

3

4

5

6

7

8

9

10

11

12

13

14

15

16

17

18

19

20

21

22

23

24

25

26

27

28

29

30

31

32

33

34

35

36

37

39

40

41

42

43

44

45

46

47

48

49

50

51

52

53

54

55

56

57

58

59

60

\section{SCHOLARONE ${ }^{m}$ Manuscripts}

http://mc.manuscriptcentral.com/jop 


\title{
Running head: CANNABIS AND EPISODIC FORESIGHT
}

Episodic foresight deficits in regular, but not recreational, cannabis users

\author{
Kimberly Mercuri ${ }^{1}$, Gill Terrett ${ }^{1}$, Julie D. Henry ${ }^{2}$, H. Valerie Curran ${ }^{3}$, \\ Morgan Elliott ${ }^{1}$, and Peter G. Rendell ${ }^{1}$
}

1 Cognition and Emotion Research Centre, School of Psychology, Australian Catholic University, Melbourne, Australia.

${ }^{2}$ School of Psychology, University of Queensland, Brisbane, Australia

${ }^{3}$ Clinical Psychopharmacology Unit, University College London, London, UK

Correspondence should be addressed to:

Kimberly Mercuri

Cognition and Emotion Research Centre

School of Psychology

Australian Catholic University

Melbourne Campus

Victoria 3065, Australia

E-mail: Kim.Mercuri@acu.edu.au

Tel: +6139953 3121

Fax: +61399533205

Word count (excl. abstract, footnotes, and reference list): 3,622

Conflict of interest declaration: None 


\begin{abstract}
Cannabis use is associated with a range of neurocognitive deficits, including impaired episodic memory. However, no study to date has assessed whether these difficulties extend to episodic foresight, a core component of which is the ability to mentally travel into one's personal future. This is a particularly surprising omission given that episodic memory is considered to be critical to engage episodic foresight. In the present study, we provide the first test of how episodic foresight is affected in the context of differing levels of cannabis use, and the degree to which performance on a measure of this construct is related to episodic memory. Sixty-one regular cannabis users (23 recreational, 33 regular) and 57 controls were assessed using an adapted version of the Autobiographical Interview. The results provide evidence of a dose-response relationship between cannabis-related impairment and both episodic foresight and episodic memory, with regular-users exhibiting greater impairment than both the recreational user and control groups. These data therefore show for the first time that cannabis related disruption of cognitive functioning extends to the capacity for episodic foresight, and are discussed in relation to their potential implications for functional outcomes in this group.
\end{abstract}

Keywords: Episodic foresight, cannabis, Autobiographical Interview, episodic memory 


\section{Introduction}

The primary ingredient responsible for the psychoactive effects of cannabis is $\Delta^{9}$ - tetrahydrocannabinol (THC) (Pertwee, 2008). THC binds to Type 1 cannabinoid (CB1) receptors, high densities of which are found in frontal and temporal brain regions (Ameri, 1999, Glass et al., 1997, Mechoulam and Parker, 2013, Quickfall and Crockford, 2006). Neuropathological changes have been observed in chronic users of this drug. For example, reductions in grey matter concentrations in temporal regions have been identified in regular long-term cannabis smokers, compared to substance naïve individuals (Matochik et al., 2005), and recreational-users (Battistella et al., 2014). Volumetric reductions of the hippocampus and amygdala have also been identified in abstinent adults (Yücel et al., 2008) and adolescents (Ashtari et al., 2011), which were dependent on both frequency and dose of cannabis smoked. In addition to these structural abnormalities, functional irregularities such as reduction in inter-hemispheric communication (Block et al., 2000) and decreased hemispheric blood flow (Lundqvist et al., 2001), have also been linked to frequent cannabis use (Block et al., 2000, Lundqvist et al., 2001).

In contrast to the consistent evidence showing structural and/or functional abnormalities associated with cannabis use, findings regarding cognitive consequences have been more variable. For example, in relation to executive functions, some studies have reported reduced performance amongst cannabis-users in decision making (Bolla et al., 2005), attention (Abdullaev et al., 2010) and response monitoring (Gruber and Yurgelun-Todd, 2005, Hester et al., 2009), while others have reported an absence of cannabis-related impairment despite evidence of altered neurological functioning (Chang et al., 2006, Elderth et al., 2004, Filbey et al., 2014, Nestor et al., 2010, Schweinsburg et al., 2010). More consistent impairment has 
been reported in relation to memory, with a number of recent reviews concluding that cannabis use is associated with memory deficits (Gonzalez, 2007, Hall, 2014, Solowij and Battisti, 2008, Schoeler et al., 2016, Curran et al., 2016). These findings may reflect the high concentrations of cannabinoid receptors located within the hippocampus and surrounding regions, areas known to be strongly involved in memory function (Jager et al., 2007).

One critically important aspect of cognition however, that has not been investigated to date amongst cannabis users is episodic foresight. At the core of episodic foresight is the ability to project oneself forward in time and imagine personally experiencing future events. This ability is considered to have immense survival value (Suddendorf and Moore, 2011) as it allows mental rehearsal of behavioral contingencies before selecting actions that will most likely achieve desired outcomes (Suddendorf and Corballis, 2007). A reduced capacity for episodic foresight in cannabis users may help explain their poor daily functioning across educational, interpersonal, and occupational environments (See Hall, 2014 for review). For example, limited episodic foresight ability may adversely impact the capacity to fulfil basic daily needs (e.g. when completing the weekly shop failure to imagine the week ahead may lead to insufficient groceries being purchased), but may also impact tasks that have more serious consequences (e.g. failure to imagine how variable traffic conditions might affect travel time to work each day may lead to consistent lateness, and in turn the perception that the individual is unmotivated and thus at risk of employment termination).

Cannabis users may be expected to exhibit episodic foresight difficulties at least in part, as a secondary consequence of cannabis-related impairment in other cognitive domains including episodic memory (Addis and Schacter, 2008, Addis et 
al., 2007, Schacter and Addis, 2007, Schacter et al., 2007). Episodic memory is of particular relevance because, according to the constructive simulation hypothesis, episodic memories of the past are crucial for episodic foresight as they provide the raw materials for the mental construction of hypothetical future events (Addis and Schacter, 2008). Possible deficits in executive functions may also place cannabis users at risk of episodic foresight impairment given that executive processes have been argued to assist in the flexible recombination of episodic memories into a new (i.e. future) time period to avoid simply recasting those past memories (Schacter and Addis, 2007, Suddendorf and Henry, 2013). As previously noted however, findings to date have been somewhat inconsistent regarding cannabis-related impairment in executive functions, and as such the extent to which it may constitute a potential risk factor for episodic foresight deficits in this group is as yet unclear.

The present study aimed to provide the first empirical assessment of whether cannabis users show disrupted capacity for episodic foresight, and whether the level of impairment is related to the frequency of cannabis use. In service of this goal, cannabis naive individuals, recreational-users, and regular-users of the drug were asked to complete a well-validated measure of this construct. The secondary goal was to examine the associations between episodic foresight and both episodic memory and executive functioning, to help clarify whether any cannabis-related difficulties with episodic foresight reflect more general impairments in either of these abilities.

\section{Method}

\section{Participants}

This study was approved by the Australian Catholic University ethics committee and conformed to the ethical standards set out in the 1964 Declaration of 
Helsinki. Fifty-seven cannabis users aged 18 to 35 years were recruited, as were 57 substance-naive controls aged 18 to 34 years who denied having any substance-use history (with the exception of alcohol). All participants were recruited using a range of community advertisements, and social networking. Exclusion criteria for all participants included: a previous or current neurological condition; a psychiatric disorder; a history of regular alcohol use (defined as 28 standard drinks per week for men and 14 for women) (Australian National Health and Medical Research Council, 2001); or a previous acquired brain injury. Participants were instructed to refrain from use of alcohol or illicit drugs in the 24 hours prior to testing. Participants were sent a reminder text message at least 24 hours prior to their testing time and abstinence was confirmed via self report on the day of testing. Participants were also excluded if English was not their first language. All participants were reimbursed up to AU\$30 ( USD\$23) for their time.

As shown in Table 1, although the groups differed on age ${ }^{1}$, with the regularuser group about 3 or 4 years on average older than the other two groups ${ }^{2}$, the groups were matched on premorbid intelligence as measured by the National Adult Reading Test (Nelson, 1982), and did not differ in reported negative affect as measured by the Hospital Anxiety and Depression Scale (Zigmond and Snaith, 1983). The sample was well balanced with respect to sex ( $45 \%$ male).

\section{[Table 1 about here]}

\section{Substance use information}

\footnotetext{
${ }^{1}$ No significant correlations were evident between future internal details (the main DV in this study) and age for the control $(p=.90)$, recreational $(p=.81)$, or heavy-user groups $(p=.90)$, thus age was not controlled for in subsequent analyses.

${ }^{2}$ Post-hoc analyses revealed significant age differences between the regular users $(\mathrm{M}=24.6, S D=$ $3.85)$ and both cannabis-naive $(M=21.30, S D=3.45)$ and recreational-users $(M=20.56, S D=3.50)$, but not between the cannabis-naive and recreational-users.
} 
The recreational cannabis-user group consisted of 23 individuals who reported their frequency of use as "weekly or less". As shown in Table 2, the group who identified as regular-users consisted of 34 participants who reported smoking cannabis at least three times per week. Further, the recreational group consisted of relatively novice users in comparison to the regular-user group, who also reported more frequent weekly use. There was no difference in age of onset between the recreational.

[Table 2 about here]

\section{Materials}

\section{Executive control}

Three measures which are particularly sensitive to mental flexibility, inhibitory control, and cognitive initiation were used as indices of executive control.

First, the Trail Making Test was used to index mental flexibility (Arbuthnott and Frank, 2000). Part A instructs participants to draw one continuous line to connect 25 scattered circles numbered from 1-25 in increasing numerical order. Part B requires the participant to connect circles that consist of letters and numbers in increasing and alternating order (1-A-2-B-3-C, etc.). The Trail Making Test was administered according to standardized guidelines (Strauss et al., 2006). Performance was measured by subtracting the time taken in seconds for Part A from Part B, with lower scores indicating better performance.

The Hayling Sentence Completion Test is a two part, timed verbal task that is sensitive to inhibitory control. The test was administered and scored following standardized instructions (Burgess and Shallice, 1997). Part A requires participants to sensibly complete 15 sentences (e.g. "She called her husband at his ...[WORK]"). 
Part B requires participants to complete another set of 15 sentences with unrelated words (e.g. "The captain wanted to stay with the sinking ...[LIPSTICK]"). Performance is measured by tallying errors and total time taken (in seconds) to complete both parts, which is then converted to a scaled score.

Finally, verbal fluency was used to provide an index of cognitive initiation (Strauss et al., 2006). For phonemic fluency, participants were instructed to generate as many exemplars of words beginning with the letters $F, A$, and $S$; excluding numbers, proper nouns or the same word with a different suffix. Each probe was allocated one minute. Total phonemic fluency was determined by subtracting errors from correct responses. To assess semantic fluency, participants were instructed to generate as many names of Animals as possible in one minute. Both measures have good sensitivity to frontal neural substrates, and appear to be valid indicators of executive control (Crawford \& Henry, 2005; Henry \& Crawford, 2004).

\section{Episodic foresight and episodic memory}

Episodic foresight and episodic memory were assessed using Addis et al. (2008) adaptation of Levine et al. (2002) Autobiographical Interview (AI). The AI is a semi-structured interview which provides an index of both episodic foresight and episodic memory by assessing episodic and non-episodic content in two temporal phase conditions (past and future). Participants are instructed to describe a personally experienced event from their past or a novel future event in response to a cue word. Six cue words chosen from the "Affective Norms for English Words List" (ANEW) (Bradley and Lang, 1999) were used to prompt event descriptions. A maximum of three minutes was allocated for each description. 


\begin{abstract}
AI cue words: Six cue words were chosen from the "Affective Norms for English Words List" (ANEW; Bradley and Lang, 1999). Guided by the ANEW valence ratings, we chose two positive (birthday, vacation), two negative (nightmare, accident) and two neutral (taxi, bench) words (valence ratings $M=8.0, M=2.0, M=$ 4.8, respectively). Three cue words (one of each valence) were administered for each temporal condition. Similar to other studies using this protocol (Irish et al., 2012) all three cues for one temporal condition were completed before administration of the three cues for the other temporal condition which allowed for a reduced cognitive load and greater facilitation of instruction comprehension. The order of cue words was counterbalanced within each temporal condition leading to six counterbalanced versions of the task.
\end{abstract}

AI testing sessions: Four interviewers were trained to follow the AI administration procedure. Prior to administration of the test cues all participants were provided with instructions and a demonstration of an event description. All three events relating to one temporal direction were completed, and this was repeated for the remaining temporal direction. Set prompts were provided when clarification of instructions or facilitation of further event description was required.

AI scoring: Interview transcripts were scored following the standardized procedures outlined by Addis et al. (2008). First, a central event was identified in the transcription for each cue word trial. Details were segmented and categorized as either internal (episodic details specific to the central event) or external (non-episodic details including: repetitions, semantic information, and information not specific to the central event). The number of internal details generated for future events was the primary measure of episodic future thinking and the number of internal details for past events indexes episodic memory. 
The transcripts were scored by three independent scorers who were blind to project aims. They were given training manuals provided by Donna Addis. These manuals included an annotated example of scoring and twenty scoring events. Inter rater reliability between the three scorers across the twenty training events was assessed on the basis of a two-way mixed-design Analysis of Variance (ANOVA) intra-class correlation analysis. The Cronbach alphas obtained with our three scorers was 0.90 for internal and 0.87 for external details. The three scorers coded portions of the full dataset and each scorer was assigned an equal proportion of transcripts from both experimental groups.

\section{Procedure}

All participants provided informed consent and were tested individually in one session of approximately three hours duration, with breaks provided as needed. Administration of cognitive assessments was counterbalanced.

\section{Data Analysis}

All statistical tests were 2-tailed. An alpha level of $p<0.05$ was considered significant, and effect sizes of ANOVA main and interaction effects were quantified using partial eta squared $\left(\eta_{p}^{2}\right)$. Effect sizes of post-hoc paired comparisons were quantified using Cohen's $d$. Data were screened for missing values and outliers. Little's MCAR test indicated that data was missing completely at random, $\chi 2(47)=$ $51.40, p=0.305$, therefore expectation maximization was used to replace missing values.

\section{Results}

\section{Background measures of cognitive functioning}


Descriptive and inferential statistics for the Trail Making Test, Hayling, and verbal fluency tests are reported in Table 1. It can be seen that there were no group differences on any of the executive function measures.

\section{Autobiographical Interview (AI)}

The first step in the analysis of the AI data involved investigating the number of internal details generated for the past and future event descriptions for the three groups. These data were analyzed using a mixed $3 \times 2$ ANOVA where the between group variable was group (control, recreational group, regular-user group), and the within group variable was temporal direction (past, future). These data are shown in Figure 1.

The independent variable of temporal phase was a main effect, $F(2,111)=171.83, p<0.001, \eta_{\mathrm{p}}{ }^{2}=0.608$ with more internal details being generated in the past $(M=189.50, S D=62.11)$ compared to the future condition $(M=127.40$, $S D=62.71$. The independent variable of primary interest, group, was a main effect, $F(2,111)=4.34, p=0.015, \eta_{\mathrm{p}}^{2}=0.073$, but did not interact with temporal phase, $F$ $(2,111)=1.25, p=0.231, \eta_{\mathrm{p}}^{2}=0.022$.

Follow up post-hoc analyses of the group differences revealed no significant differences in the number of internal details generated between the control group and recreational-users $(p=.545)$. However, differences were identified between the control group and regular-users $(p=0.013, d=3.57)$ as well as between the recreational and regular-users $(p=0.011, d=3.65)$, with the regular cannabis users performing less well than the control group and recreational-users ${ }^{3}$.

\footnotetext{
${ }^{3}$ Analysis of number of external details is not reported in the main text as they are of minimal interest compared to the number of internal details (which was the key DV in this study; briefly, there was a main effect of temporal phase and group, $F \mathrm{~s} \geq 3.71, p \leq .028$, with more external details generated in the past compared to the future, and more external details generated by the control group than regular
} 
[Figure 1 about here]

\section{Correlations}

To investigate cognitive correlates of episodic foresight, correlation analyses were conducted between episodic foresight (future internal details), and episodic memory (past internal details) and the three measures of executive functioning for the three groups separately. As shown in Table 2 better episodic memory was associated with better episodic foresight ability for all three groups. Of the three measures of executive functioning, only verbal fluency moderately correlated with episodic foresight, but only for controls and regular cannabis users.

[Table 3 about here]

\section{Discussion}

By providing the first empirical assessment of episodic foresight ability in cannabis users, these data provide further important insights into the neurocognitive effects of cannabis use. The results indicate that, relative to controls and recreationalusers, episodic foresight is disrupted in individuals who regularly use this drug. Specifically, regular cannabis users show a substantial deficit in their capacity to generate episodic details when asked to imagine novel future scenarios. These data therefore complement, but also extend, prior research showing cannabis-related deficits in related future-oriented cognitive abilities, such as prospective memory (Bartholomew et al., 2010, Fisk and Montgomery, 2007, Montgomery. et al., 2012) and planning (Harvey et al., 2007, Montgomery. et al., 2012), by showing that the capacity for episodic foresight is also adversely affected. The only other study to assess episodic foresight in the context of chronic substance abuse (long-term opiate al. (46) for explanation of why external details on the AI measure is of secondary interest. 
users) also identified significant impairments (Mercuri et al., 2014). The current study shows that episodic foresight deficits extend to cannabis users, and importantly appear to be a function of the frequency of cannabis use, with deficits apparent in regular but not recreational-users.

The poorer performance of the regular cannabis-users relative to the control and recreational-users across both temporal phase conditions (future and past) indicates not only a deficit in episodic foresight, but also a deficit in episodic memory. This finding is consistent with prior literature that has identified cannabisrelated deficits in episodic memory (for reviews see Crane et al., 2013, Ranganathan and D’Souza, 2006, Curran et al., 2016). As noted previously, a central tenet of the constructive simulation hypothesis is that past memories provide the basic building blocks for the creation of novel future scenarios in our imagination. It is therefore possible that the poorer episodic foresight shown by the regular cannabis-users reflects, at least in part, a reduced ability to recall the past memories needed to mentally create hypothetical future experiences. Further support for this possibility is provided by the strong pattern of correlations showing that better episodic memory was associated with better episodic foresight performance for all three groups, findings which are consistent with both the constructive simulation hypothesis and with previous finding involving other clinical groups (see Schacter and Addis, 2007 for review).

Interestingly, Mercuri et al. (2014) identified a different profile of impairment for opiate users, showing them to perform more poorly than controls on episodic foresight but similarly to controls when recalling past events. The deficits in episodic memory found for regular cannabis (but not opiate) users may reflect the fact that there are greater densities of cannabinoid receptors in areas responsible for memory 
recall, potentially rendering regular cannabis users particularly vulnerable to episodic memory disruption. Because Mercuri et al. (2014) identified significant correlations between measures of episodic foresight and executive control, they argued that episodic foresight difficulties in the context of opiate use may reflect problems flexibly recombining episodic memories into a novel future event, rather than a reduced ability to recall the memories needed for construction of those future events (i.e., a failure of executive control mechanisms, as opposed to episodic memory impairment). By contrast, the results of the current study suggest that any contribution of executive dysfunction to episodic foresight difficulties in cannabis users is likely to be minimal. Specifically, no group differences were identified on the executive function measures, and only one of the three executive measures (i.e. verbal fluency) was related to episodic foresight.

The current data have potentially important functional implications. As noted previously, episodic foresight has an anticipatory element which allows for the capacity to construct and work through various hypothetical scenarios before executing any goal directed action. Difficulties engaging episodic foresight may therefore limit the frequency of behavioral contingencies constructed, restricting the range of actions that would potentially be available to achieve desired goals. Impaired episodic foresight may therefore contribute to the maladaptive decision making observed in long-term cannabis users that sees the fulfilment of current goals prioritised over the future goals that may potentially yield greater rewards (Grant et al., 2000). In addition, difficulties with episodic foresight may potentially jeopardize therapeutic progress as many relapse prevention strategies require an element of future thought. Techniques such as goal setting, role playing how to decline future drug offers, and weighing up future consequences of achieving abstinence all require 
projection to an unfamiliar future, free of narcotics. Therefore, in the context of relapse prevention, an absence of targeted cognitive rehabilitation strategies aimed at enhancing the capacity for episodic foresight may have only limited efficacy.

It is important to note that the current data indicate that episodic foresight is unlikely to be disrupted by recreational use of cannabis, with recreational-users performing as well as controls. Further work is now needed to establish whether it is the total length of time, and/or the absolute frequency of use that is most important to understanding neurocognitive impairment in regular-users. This is because in the present study the regular-user group consisted of individuals who reported both more frequent weekly use than the recreational-users (at least three times per week vs. up to one time per week) and also a longer duration of lifetime use. Specifically, ninety-one percent of the regular-user group reported at least one-year duration of substance use, with $62 \%$ of this group indicating at least three years of consistent cannabis use. By contrast, the majority of the recreational-user group (70\%) reported their lifetime duration of use to be less than three years.

There were a number of limitations in the present study. First, classification of cannabis users into groups was based on a self-report measure of cannabis use which, according to a recent study by Hindocha et al. (2017) is a dramatic overestimate of actual cannabis exposure. However, this method of measurement is prevalent in drug use research, and is therefore a limitation of all cohort-based research due to the absence of biological measures, such as cannabinoids in hair samples. Second, although there was no significant difference in performance between males and females on any of the observed measures, future research should seek to balance the gender distribution across groups. A final limitation of these data is the homogeneity of substance use history among the cannabis-using participants. Although cannabis 
was reported by all to be the drug of preference, for the cannabis-using groups, a history of poly-drug use was apparent for most participants in this group. However, this profile is common amongst cannabis users in previous studies investigating the cognitive impact of substance use.

In conclusion, the present study supports previous findings showing that regular cannabis-use can disrupt the capacity for mental time travel into the past, but demonstrates for the first time that this extends to the capacity for episodic foresight. However, this deficit was restricted to regular, rather than recreational-users. Further research is now needed to clarify the mechanisms that may explain the observed impairments in the context of chronic cannabis use. These issues are particularly important given the widespread use of cannabis and the recent increase in its access, and well-documented psychosocial consequences associated with its use. 


\section{Funding and Disclosure}

This research was supported by a Discovery Research Grant (DP110100652C) from the Australian Research Council.

\section{Acknowledgements}

We would like to thank all of our participants who generously volunteered their time to participate in our project. We also acknowledge the help of Fiona Sparrow in the transcribing of participant interviews as well as Sandra RaponiSaunders, Burcu Akdeniz, and Jake Linardon for the scoring of participant interviews. Finally, we would like to thank Donna Addis for generously sharing the materials, and her advice on conducting and scoring of the adapted Autobiographical Interview AI. 


\section{References}

ABDULLAEV, Y., POSNER, M. I., NUNNALLY, R. \& DISHION, T. J. 2010. Functional MRI evidence for inefficient attentional control in adolescent chronic cannabis abuse. Behavior Brain Research, 215, 45-57.

ADDIS, D. R. \& SCHACTER, D. L. 2008. Constructive episodic simulation: temporal distance and detail of past and future events modulate hippocampal engagement. Hippocampus, 18, 227-237.

ADDIS, D. R., WONG, A. T. \& SCHACTER, D. L. 2007. Remembering the past and imagining the future: common and distinct neural subtrates during event construction and elaboration. Neuropsychologia, 45.

ADDIS, D. R., WONG, A. T. \& SCHACTER, D. L. 2008. Age-related changes in the episodic simulation of future events. Psychological Science, 19, 33-41.

AMERI, A. 1999. The effects of cannabinoids on the brain. Progress Neurobiology, $58,315-348$.

ARBUTHNOTT, K. \& FRANK, J. 2000. Trail Making Test, Part B as a measure of executive control: Validation using a set-switching paradigm. Journal of Clinical and Experimental Neuropsycholgy, 22, 518-258.

ASHTARI, M., AVANTS, B., CYCKOWSKI, L., CERVELLIONE, K. L., ROOFEH, D., COOK, P., GEE, J., SEVY, S. \& KUMRA, S. 2011. Medial temporal structures and memory functions in adolescents with heavy cannabis use. Journal of Psychiatric Research, 45, 1055-1066.

AUSTRALIAN NATIONAL HEALTH AND MEDICAL RESEARCH COUNCIL 2001. Australian alcohol guidelines: Health risks and benefits. Canberra: Commonwealth of Australia.

BARTHOLOMEW, J., HOLROYD, S. \& HEFFERNAN, T. M. 2010. Does cannabis use affect prospective memory in young adults? Journal of Psychopharmacology, 24, 241-246.

BATTISTELLA, G., FORNARI, E., ANNONI, J.-M., CHTIOUI, H., DAO, K., FABRITIUS, M., FAVRAT, B., MALL, J.-F., MAEDER, P. \& GIROUD, C. 2014. Long-term effects of cannabis on brain structure. Neuropsychopharmacology, 39, 2040-2048.

BLOCK, R. I., O'LEARY, D. S., HICHWA, R. D., AUGUSTINACK, J. C., BOLES PONTO, L. L., GHONEIM, M. M., ARNDT, S., EHRHARDT, J. C., HURTIG, R. R., WATCKINS, G. L., HALL, J. A., NATHA, P. E. \& ANDREASEN, N. C. 2000. Cerebellar hypoactivity in frequent marijuana users. Brain Imaging, 11, 749-753.

BOLLA, K. I., ELDERTH, D. A., MATOCHIK, J. A. \& CADET, J. L. 2005. Neural substrates of faulty decision-making in abstinent marijuana users. Neuroimage, 26, 480-492.

BRADLEY, M. M. \& LANG, P. J. 1999. Affective Norms for English Words (ANEW): Stimuli, instruction manual and affective ratings Technical Report $C-1$ Gainesville, FL, The Center for Research in Psychophysiology, University of Florida.

BURGESS, P. W. \& SHALLICE, T. 1997. The Hayling and Brixton Tests. Test Manual, UK, Thames Valley Test Company.

CHANG, L., YAKUPOV, R., CLOAK, C. \& ERNST, T. 2006. Marijuana use is associated with reorganized visual-attention network and cerebellar hypoactivation. Brain, 129, 1096-1112. 
CRANE, N. A., SCHUSTER, R. M. \& GONZALEZ, R. 2013. Preliminary evidence for a Sex-specific relationship between amount of cannabis use and neurocognitive performance in young adult cannabis users. Journal Internation Neuropsychological Society, 19, 1009-1015.

CURRAN, H. V., FREEMAN, T. P., MOKRYSZ, C., LEWIS, D. A., MORGAN, C. J. A. \& PARSONS, L. H. 2016. Keep off the grass? Cannabis cognition and addiction. Nature Reviews Neuroscience, 17, 293-306.

ELDERTH, D. A., MATOCHIK, J. A., CADET, J. L. \& BOLLA, K. I. 2004. Abnormal brain activity in prefrontal brain regions in abstinent marijuana users. neuroimage, 23, 914-920.

FILBEY, F. M., ASLAN, S., CALHOUN, V. D., SPENCE, J. S., DAMARAJU, E., CAPRIHAN, A. \& SEGALL, J. 2014. Long-term effects of marijuana use on the brain. PNAS, 111, 16913-16918.

FISK, J. E. \& MONTGOMERY, C. 2007. Everyday memory deficits in ecstasypolydrug users. Journal of Psychopharmacology, 21, 707-717.

GLASS, M., DRAGUNOW, M. \& FAULL, R. L. 1997. Cannabinoid receptors in the human brain: a detailed anatomical and qunatitative autoradicographic study in the fetal, neonatl and adult human brain. Neuroscience, 77, 299-318.

GONZALEZ, R. 2007. Acute and non-acute effects of cannabis on brain functioning and neuropsychological performance. Neuropsychological Review, 17, 347361.

GRANT, S., CONTOREGGI, C. \& LONDON, E. D. 2000. Drug abusers show impaired performance in laboratory tests of decision making. Neuropsychologia, 38, 1180-1187.

GRUBER, S. A. \& YURGELUN-TODD, D. A. 2005. Neuroimaging of marijuana smokers during inhibitory processing: a pilot investigation. Brain Research Cognitive Brain Research, 23, 107-118.

HALL, W. 2014. What has research over the past two decades revealed about the adverse effects of recreational acannabis use? Addiction.

HARVEY, M., SELLMAN, J. D., PORTER, R. J. \& FRAMPTON, C. M. 2007. The relationship between non-acute adolescent cannabis use and cognition. Drug and Alcohol Review, 26, 309-319.

HESTER, R., NESTOR, L. \& GARAVAN, H. 2009. Impaired error awareness and anterior cingulate cortex hypoactivity in chronic cannabis users. Neuropsychopharmacology, 34, 2450-2458.

HINDOCHA, C., FREEMAN, T. P. \& CURRAN, H. V. 2017. Anatomy of a joint: Comparing self-reported and actual dose of cannabis and tobacco in a joint, and how these are influenced by controlled acute administration. Cannabis and Cannabinoid Research, 2, 217-223.

IRISH, M., ADDIS, D. R., HODGES, J. R. \& PIGUET, O. 2012. Considering the role of semantic memory in episodic future thinking: evidence from semantic dementia. Brain, 135, 2178-91.

JAGER, G., VAN HELL, H. H., MDE WIN, M. M. L., KAHN, R. S., VAN DEN BRINK, W., VAN REE, J. M. \& RAMSEY, N. F. 2007. Effects of frequent cannabis use on hippocampal activity during an associative memory task. European Neuropsychopharmacology, 17, 289-297.

LEVINE, B., SVOBODA, E., HAY, J. F., WINOCUR, G. \& MOSCOVITCH, M. 2002. Aging and autobiographical memory: Dissociating episodic from semantic retrieval. Psychology and Aging, 17. 
LUNDQVIST, T., JÖNSSON, S. \& WARKENTIN, S. 2001. Frontal lobe dysfunction in long-term cannabis users. Neurotoxicology and Teratology, 23, 437-443.

MATOCHIK, J. A., ELDERTH, D. A., CADET, J.-L. \& BOLLA, K. I. 2005. Altered brain tissue composition in heavy marijuana users. Drug and Alcohol Dependence, 77, 23-30.

MECHOULAM, R. \& PARKER, L. A. 2013. The endocannabinoid system and the brain. Annual Review of Psychology, 64, 21-47.

MERCURI, K., TERRETT, G., HENRY, J., BAILEY, P. E., CURRAN, H. V. \& RENDELL, P. G. 2014. Episodic foresight deficits in long term opiate use. Psychopharmacology.

MONTGOMERY., C., SEDDON., A. L., FISK., J. E., MURPHY., P. N. \& JANSARI, A. 2012. Cannabis-related deficits in real-world memory. Humam Psychopharmacology, 27, 217-225.

NELSON, H. E. 1982. The National Adult Reading Test (NART): Test manual, Windsor, NFER-Nelson.

NESTOR, L., HESTER, R. \& GARAVAN, H. 2010. Increased ventrial straital BOLD activity during non-drug reward anticipation in cannabis users. Neuroimage, 49, 1133-1143.

PERTWEE, R. G. 2008. The diverse CB1 and CB2 receptor pharmacology of three plant cannabinois: delta-9-terahydrocannabinol, cannabidiol and delta-9terahydrocannabivarin. British Journal of Pharmacology, 153, 199-215.

QUICKFALL, J. \& CROCKFORD, D. 2006. Brain neuroimaging in cannabis use: A review. The Journal of Neuropsychiatry and Clinical Neurosciences, 18, 318332.

RANGANATHAN, M. \& D'SOUZA, D. C. 2006. The acute effects of cannabinoids on memory in humans: A review. Psychopharmacology (Berl) 188, 425-444.

SCHACTER, D. L. \& ADDIS, D. R. 2007. The cognitive neuroscience of constructive memory: remembering the past and imagining the future.

Philosophical Transactions of the Royal Society Biological Sciences, 362, 773-786.

SCHACTER, D. L., ADDIS, D. R. \& BUCKNER, R. L. 2007. Remembering the past to imagine the future: the prospective brain. Nature Reviews Neuroscience, 8 , 657-661.

SCHOELER, T., KAMBEITZ, J., BEHLKE, I., MURRAY, R. \& BHATTACHARYYA, S. 2016. The effects of cannabis on memory function in users with and without psychotic disorder: findings from a combined metaanalysis. Psychological Medicine, 46, 177-188.

SCHWEINSBURG, A. D., SCHWEINSBURG, B. C., NAGEL, B. J., EYLER, L. T. $\&$ TAPERT, S. F. 2010. Neural correlates of verbal learning in adolescent alcohol and marijuana users. Addiction, 106, 564-573.

SOLOWIJ, N. \& BATTISTI, R. 2008. The chronic effects of cannabis on memory in humans: A review. Current Drug Abuse Reviews, 1, 81-98.

STRAUSS, E., SHERMAN, E. M. S. \& SPREEN, O. 2006. A Compendium of Neuropsychological Tests: Administration, norms and commentary, New York, Oxford University Press.

SUDDENDORF, T. \& CORBALLIS, M. C. 2007. The evolution of foresight: What is mental time travel, and is it unique to humans? Behavioral and Brain Sciences, 30, 229-351.

SUDDENDORF, T. \& HENRY, J. D. 2013. Proximate and ultimate perspectives on memory. Journal of Applied Research in Memory and Cognition, 4, 264-267. 
SUDDENDORF, T. \& MOORE, C. 2011. Introduction to the special issue: The development of episodic foresight. Cognitive Development, 26, 295-298.

YÜCEL, M., SOLOWIJ, N., RESPONDECK, C., WHITTLE, S., FORNITO, A., PANTELIS, C. \& LUBMAN, D. I. 2008. Regional brain abnormalities associated with long-term heavy cannabis use. Archives of General Psychiatry, 65, 694-701.

ZIGMOND, A. S. \& SNAITH, R. P. 1983. The Hospital Depression and Anxiety Scale. Acta Psychiatrica Scandinavia, 67, 361-370. 
Running head: CANNABIS AND EPISODIC FORESIGHT

\section{Table 1}

Participant Characteristics

\begin{tabular}{|c|c|c|c|c|}
\hline & $\begin{array}{l}\text { Substance-naïve } \\
\text { control group } \\
n=57\end{array}$ & $\begin{array}{l}\text { Recreational- } \\
\text { user group } \\
n=23\end{array}$ & $\begin{array}{l}\text { Regular-user } \\
\text { group } \\
n=34\end{array}$ & $\begin{array}{l}\text { Statistical } \\
\text { sig }\end{array}$ \\
\hline Age (in years) & $21.3(3.5)$ & $20.5(2.2)$ & $24.7(3.9)$ & $<0.001$ \\
\hline Estimated IQ & $110.7(4.8)$ & $109.8(5.2)$ & $111.0(5.0)$ & NS \\
\hline HADS & $8.3(4.1)$ & $10.8(7.5)$ & $9.4(5.7)$ & NS \\
\hline \multicolumn{5}{|l|}{ Executive Functions } \\
\hline Verbal Fluency & $58.0(16.8)$ & $63.8(12.4)$ & $60.0(15.0)$ & NS \\
\hline Cognitive Flexibility & $28.5(14.3)$ & $34.2(17.5)$ & $36.5(22.7)$ & NS \\
\hline Inhibition & $6.2(0.8)$ & $6.2(0.8)$ & $6.1(0.7)$ & NS \\
\hline Alcohol(Yes:No) & $55: 2$ & $22: 1$ & $25: 9$ & \\
\hline
\end{tabular}

Table 2

Cannabis use patterns for each cannabis group

\begin{tabular}{lcc}
\hline & $\begin{array}{c}\text { Recreational-user } \\
\text { group } \\
n=23\end{array}$ & $\begin{array}{c}\text { Regular-user } \\
\text { group } \\
n=34\end{array}$ \\
\hline Age of onset & $18.02(2.51)$ & $17.21(3.16)$
\end{tabular}

Frequency (days p/week)

$\begin{array}{lcc}<2 \text { days } & 23 & 0 \\ 3-4 & - & 8 \\ 5-6 & - & 10 \\ \text { Daily } & - & 16\end{array}$

\section{Duration of lifetime use}

$<6$ months

1

$6-12$ months $\quad 11 \quad 2$

$1-3$ years $\quad 4 \quad 10$

$3-5$ years $\quad 4 \quad 8$

$>5$ years $\quad 3 \quad 13$




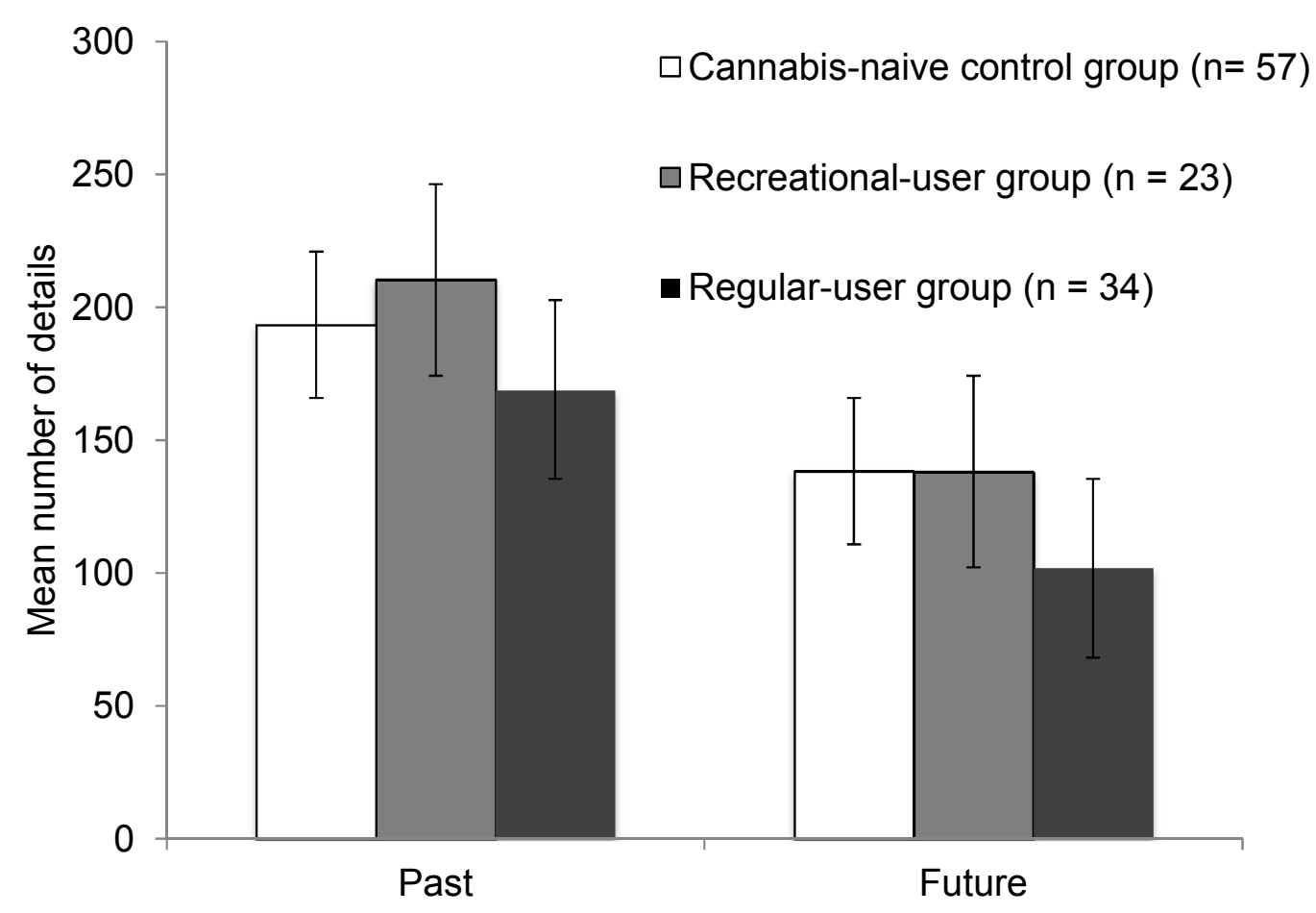

Figure 1. Mean number of internal details generated on the AI as a function of group status (substance-naivecontrol group, $n=57$; recreational cannabis-smoker group, $n=23$, regular cannabis-smoker group, $n=34$ ) and temporal direction. (Error bars depict standard error of the mean) 


\section{Table 3}

Pearson's product correlation coefficients $(r)$ between episodic foresight, and five other measures: episodic memory, overall cognitive functioning (FSIQ) and three measures of executive functioning as a function of group status

\begin{tabular}{|c|c|c|c|}
\hline & $\begin{array}{c}\text { Substance- } \\
\text { naivecontrol } \\
\text { group } \\
n=57 \\
\end{array}$ & $\begin{array}{c}\text { Recreational- } \\
\text { user group } \\
n=23\end{array}$ & $\begin{array}{l}\text { Regular-user } \\
\text { group } \\
n=34\end{array}$ \\
\hline & $\begin{array}{l}\text { Episodic } \\
\text { Foresight }\end{array}$ & $\begin{array}{l}\text { Episodic } \\
\text { Foresight }\end{array}$ & $\begin{array}{l}\text { Episodic } \\
\text { Foresight }\end{array}$ \\
\hline Episodic memory & $0.8^{* *}$ & $0.7^{* *}$ & $0.3^{*}$ \\
\hline FSIQ & 0.1 & 0.1 & $0.3^{*}$ \\
\hline Cognitive flexibility & 0.1 & -0.2 & -0.05 \\
\hline Cognitive inhibition & 0.2 & 0.1 & $<0.01$ \\
\hline Verbal fluency & $0.4^{* *}$ & -0.3 & $0.5^{* *}$ \\
\hline
\end{tabular}

